\title{
Tinjauan Sistem Pendaftaran Pasien Rawat Inap Di RSU Mitra Sejati Medan
}

\author{
${ }^{1}$ Suheri Parulian Gultom, ${ }^{2}$ Febri Yani Friska Ginting \\ Program Studi D-III Perekam dan Informasi Kesehatan, Universitas Imelda Medan
}

\begin{tabular}{l} 
Article Info \\
\hline Article history: \\
Received august 13, 2020 \\
Revised August 26, 2020 \\
Accepted August 29, 2020 \\
\hline
\end{tabular}

\section{Keywords:}

Inpatient Registration Officer Registration System Registration Officer

\begin{abstract}
Patient registration is the foremost part of Hospital service, because the patient registration records the identity and requirements of his visit to the hospital, and at the time of registration the patient gets the first impression of the hospital's services. The purpose of this study was to determine the stages of admission of inpatients at Mitra Sejati Hospital Medan and to find out the obstacles in the implementation of inpatient admissions at Mitra Sejati Hospital in Medan. The type of research used is descriptive using a quantitative approach, the research sample is 5 inpatient registration officers, data collection was done by interviewing the inpatient registration officer. The results showed that the registration stages of inpatients at Mitra Sejati Hospital Medan had not met the regulations of the PERMENKES (2008) on the naming and use of KIB and KIUP. It can be concluded that Mitra Sejati Hospital Medan has not implemented the naming rules according to the PERMENKES and has not implemented the use of KIB and KIUP. It can be suggested that registration officers should have implemented a naming system according to the PERMENKES rules and already have to implement the use of KIB and KIUP to make it easier for officers to register patients and find patient medical record files. For education, to explain more to students how the stages of inpatient registration are. For inpatient registration officers at Mitra Sejati Hospital Medan, it is better if they need to carry out training on the stages of patient acceptance / registration to improve a more effective way of working.
\end{abstract}

This is an open access article under the CC BY-SAlicense.

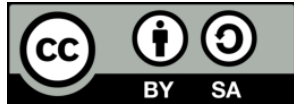

\section{Corresponding Author:}

Suheri Parulian Gultom,

Program Studi D-III Perekam dan Informasi Kesehatan,

Universitas Imelda Medan,

Jl. Bilal No. 52 Kelurahan Pulo Brayan Darat I Kecamatan Medan Timur, Medan - Sumatera Utara.

Email: suheriparuliangultom@gmail.com

\section{PENDAHULUAN}

Meningkatkan mutu pelayanan kesehatan di rumah sakit Departmen Kesehatan RI telah mengeluarkan kebijakan yang menjadi pedoman bagi penyelenggaraan pembangunan kesehatan yang dilaksanakan oleh pemerintah maupun swasta. Sistem informasi rumah sakit merupakan salah satu komponen yang penting dalam mewujudkan upaya peningkatan mutu tersebut. Sistem informasi rumah sakit secara umum bertujuan untuk 
mengintegrasikan sistem informasi dari berbagai subsistem dan mengolah informasi yang diperlukan sebagai pengambilan keputusan (Wandy, 2009).

Manajemen adalah ilmu terapan yang dapat dimanfaatkan dalam berbagai organisasi untuk membantu seorang manajer memecahkan masalah yang muncul dalam sebuah organisasi, manajemen juga dapat diterapkan dalam organisasi pelayanan kesehatan.

Menurut (Notoatmojo, 2010), Manajemen kesehatan adalah suatu kegiatan atau suatu seni untuk mengatur para petugas kesehatan dan nonpetugas kesehatan guna meningkatkan kesehatan masyarakat melalui program kesehatan. Manajemen rumah sakit mengendaki pengelolaan rumah sakit yang efektif dan efisien. Efektif dalam arti tingkat keberhasilan penanganan terhadap pasien cukup tinggi dan efisien berarti optimal dalam penggunaan sumber daya rumah sakit yang ada. Suatu upaya serius dan terencana harus ditempuh agar keinginan tersebut dapat tercapai (Wandy, 2009).

Pengelolaan data dirumah sakit merupakan suatu komponen yang penting dalam mewujudkan suatu sistem informasi di rumah sakit. Pengelolaan data secara manual, mempuyai banyak kelemahan, selain membutuhkan waktu yang lama, keakuratannya juga kurang dapat diterima, karena kemungkinan kesalahan sangat besar. Dengan dukungan teknologi informasi yang ada sekarang ini, pekerjaan pengolahan data dengan cara manual dapat digantikan dengan suatu sistem informasi menggunakan komputer. Selain lebih cepat dan mudah, pengelolaan data juga dapat lebih akurat (Handoyo, 2008).

Sistem Informasi Manajemen Rumah Sakit (SIMRS) adalah suatu tatanan yang berurusan dengan pengumpulan data, penyajian informasi, analisis dan penyimpulan informasi serta penyimpanan informasi yang dibutuhkan untuk kegiatan rumah sakit (Wenny, 2008).

Sistem registrasi pasien yaitu mencangkup proses pendaftaran pasien terdiri atas pencatatan identitas pasien, pemberian nomor rekam medis, pencatatan kamar pasien, dan pencatatan tanggal masuk. Menurut (DEPKES, 1997) pendaftaran pasien adalah awal dari keseluruhan proses rekam medis atau bisa dikatakan pendaftaran adalah pelayanan yang pertama kali didapatkan oleh seorang pasien saat tiba di rumah sakit, dalam proses pendaftaran inilah pasien mendapat kesan yang baik ataupun tidak baik dari suatu pelayanan dari rumah sakit. Dalam sistem pendaftaran, biasanya pasien diterima sabagai pasien rawat jalan, rawat inap, dan rawat UGD. Sistem pendaftaran pasien ini dapat dibedakan menjadi pendaftraan pasien lama dan pasien baru. Pendaftran pasien baru akan dilaksanakan dengan mengisi formulir pendaftaran pasien baru untuk mendapatkan data pasien yang akan di masukan ke komputer, sedangkan pendaftaran pasien lama, dilakukan dengan mencari berkas rekam medis pasien sesuai dengan nomor rekam medis yang tercantum dalam kartu berobat.

Menurut penelitian yang berjudul Rancangan Sistem Informasi Pendaftaran Pasien Rawat Jalan Berbasis Visual Basic Di Rumah Sakit Umum Sundari Tahun 2015 menyatakan implementasi program yang digunakan komputer pada sistem informasi rekam medisnini menggunakan bahasa pemrograman Visual Basic 6.0 untuk mempermudah proses pembuatan sistem informasi dan implementasi produk. Sistem informasi yang dibuat dapat mengatasi permasalahan-permasalahan yang ada di Rumah Sakit Umum Sundari. Media penyimpanan, pengolahan data pasien, rekam medis, dan obat sudah terkomputerisasi sehingga proses pelayanan kesehatan masyarakat dapat dilakukan dengan cepat dan mudah serta terhindar dari kesalahan (Ritonga, 2016).

Penelitian lain yang berjudul Faktor-Faktor Penghambat Pelayanan Di Tempat Pendaftaran Pasien BPJS Rawat Jalan Di Rumah Sakit Sari Mutiara, Lubuk Pakam Tahun 2019 menyatakan agar selalu dilakukan keterbukaan atas informasi berkas persyaratan pendaftaran dan pelayanan kesehatan terhadap peserta BPJS Kesehatan. Bentuk penyimpanan dokumen rekam medis sebaiknya menggunakan dua sistem yaitu sentralisasi 
dan desentralisasi juga tracer agar keberadaan dokumen rekam medis dapat diketahui yaitu dipinjam atau sudah dikembalikan tetapi tidak sesuai dengan urutan nomor rekam medisnya (Hutauruk \& Gurning, 2019).

Proses pendaftaran pasien di RSU Mitra Sejati Medan terbagi atas pendaftaran pada jam kerja yaitu pendaftran pasien ASKES, JKN, BPJS dan sebagainya, pendaftaran pasien pribadi, dan pendaftaran pasien di luar jam kerja yaitu pendaftaran IGD.

Petugas pendaftaran pasien harus menguasai kegiatan yang ada di tempat penerimaan pasien. Selain beberapa istilah dalam register diatas ada beberapa kegiatan yang harus dipahami oleh petugas pemerimaan pasien terkait dengan manajemen penerimaan pasien fasilitas pelayanan kesehatan. Beberapa kegiatan penerimaan pasien tersebut meliputi identifikasi pasien, penamaan pasien, penomoran berkas rekam medis, dan registrasi pasien. Masing mesing kegiatan di atas dikerjakan sesuai dengan prosedur yang berlaku.

Survei awal yang telah dilakukan oleh penulis Di RSU Mitra Sejati Medan tahun 2017, didapatkan bahwa hampir semua berkas rekam medis pasien belum memenui aturan penamaan yang sesuai dengan aturan Permenkes No 269 Tahun 2008. Berdasarkan hasil survei awal yang telah dilakukan penulis maka penulis berniat melakukan penelitian dengan judul "Tinjauan Sistem Pendaftaran Pasin Rawat Inap Di RSU Mitra Sejati Medan" yang akan membahas tentang identifikasi pasien, penamaan pasien, penomoran berkas rekam medis, dan registrasi pasien di RSU Mitra Sejati Medan.

\section{METODE PENELITIAN}

\section{A. Jenis Penelitian}

Jenis penelitian yang dilakukan ini adalah deskriptif dengan menggunakan pendekatan kuantitatif. Metode deskriptif adalah metode penelitian yang dilakukan dengan tujuan utama membuat gambaran atau deskriptif tentang suatu keadaan secara objektif. Metode ini digunakan untuk melihat gambaran registrasi pendaftaran pasien di RSU Mitra Sejati Medan (Notoadmojo, 2010).

B. Waktu dan Tempat Penelitian

Waktu penelitian ini dimulai pada bulan Juni s/d Juli 2017. Tempat penelitian adalah di RSU Mitra Sejati Medan yang beralamat di JL. Jendral Abdul Haris Nasution No. 7, Pangkalan Mansyur, Medan Johor, Sumatera Utara.

C. Populasi dan Sampel

Populasi adalah keseluruhan subjek Penelitian. (Priyo, 2008) yang menjadi populasi dalam penelitian ini adalah semua petugas pendaftran rawat inap di Rumah Sakit Mitra Sejati Medan yaitu berjumlah 5 Orang. (Fajar. Dkk, 2009). Sampel adalah sebagian saja dari seluruh jumlah populasi, yang diambil dari populasi dengan cara sedemikian rupa sehingga dapat dianggap mewakili seluruh anggota populasi (Priyo, 2008). Pengambilan sampel menggunakan cara teknik total populasi yaitu seluruh petugas pendaftran pasien rawat inap di Rumah Sakit Mitra Sejati Medan yaitu berjumlah 5 orang.

D. Variabel Penelitian

Variabel adalah suatu yang digunakan sbagai ciri, sifat, atau ukuran yang dimiliki atau didapat oleh satuan penelitian tentang suatu konsep pengertian tertentu (Notoatmodjo, 2010).

E. Definisi Operasional

Untuk membatasi ruuang lingkup atau pengertian variabel-variabel yang diteliti/diamati, perlu sesekali variabel-variabel tersebut diberi batasan atau definisi operasional (Notoatmodjo, 2010).

Dengan memperhatikan latar belakan dan perumusan masalah tersebut, maka definisi operasional variabel dari penelitian ini adalah sebagai berikut:

1. Jumlah petugas rekam medis di tempat pendaftaan pasien Rawat Inap. 
2. SOP (Standar Operation Prosedure) yaitu suatu prosedur yang telah dibuat dan ditetapkan dan ternyata hasilnya baik, memenuhi maksud, kemudian dibakukan menjadi pegangan pelaksanaan pendaftaran pasien.

3. SDM (Sumber Daya Manusia) yaitu petugas yang ahli dibagian pendaftaran pasien.

F. Instrumen Penelitian

Instrumen penelitian adalah alat atau fasilitas yang digunakan oleh peneliti dalam mengumpulkan data agar pekerjaannya lebih mudah dan hasilnya lebih baik (Arikunto, 2007). Instrumen yang digunakan dalam penelitian ini adalah:

a. Pedoman wawancara

Pedoman wawancara ini berisi daftar pertanyaan yang akan diajukan oleh peneliti kepada subjek penelitian terkait pendaftaran pasien.

b. Alat tulis

Alat tulis pada penelitian ini adalah pena dan buku yang digunakan untuk mencatat hasil penelitian.

G. Tehnik Pengolahan dan Analisis Data

Menurut (Notoadmojo, 2010) rancangan analisa data hasil penelitian di formulasikan dengan menempuh langkah-langkah yang dimulai dari:

a. Editing

Tanda/kode berbentuk angka pada masing-masing jawaban. Adalah memeriksa daftar pertanyaan yang telah diserahkan oleh pengumpulan data. Pemeriksaan daftar pertanyaan yang telah selesai ini dilakukan terhadap kelengkapan jawaban, keterbacaan tulisan dan revisi jawaban.

b. Klasifikasi

Penyusunan bersistem dalam kelompok atau golongan menurut kaidah standar yang diterapkan.

c. Penyajian data

Salah satu kegiatan dalam pembatan laporan hasil penelitian yang telah dilakukan agar dapat dipahami dan dianalisi sesuai dengan tujuan yang diinginkan.

\section{HASIL DAN PEMBAHASAN}

\subsection{Hasil}

Berdasarkan penelitian yang dilakukan penulis mengenai "Tinjauan Sistem Penerimaan Pasien Rawat Inap di RSU Mitra Sejati Medan Tahun 2017" dengan melakukan wawancara secara mendalam kepada 5 petugas pendaftaran di Rumah Sakit tersebut, peneliti menemukan jawaban yang sama dari lima petugas yang sudah di wawancari dengan pertanyaan pertama yaitu "apa yang dilakukan petugas apendaftaran pertama kali saat melayani pasien rawat inap yang ingin berobat ke RSU Mitra sejati medan?" jawaban dari petugas adalah Sistem penerimaan pasien rawat inap di RSU Mitra Sejati Medan menurut petugas pendaftaran yaitu petugas mengidentifikasi pasien dengan mewawancarai pasien/keluarga pasien yang mendaftar.

Untuk pertanyaan kedua yaitu "apa saja syarat yang harus diperlukan pasien untuk bisa rawat ianap di RSU Mitra Sejati Medan?” Jawaban dari petugas adalah, untuk bisa rawat inap di RSU Mitra Sejati Medan pasien harus memenuhi syarat-syarat pendaftaran yaitu, jika pasien adalah pasien umum maka harus menunjukan KTP pasien dan memberikan panjar biaya perawatan. Namun bila pasien adalah pasien BPJS/Asuransi, harus menunjukan KTP, dan kartu BPJS/Asuransi.

Pertanyaan ketiga "jika pasien ingin berobat dan diharuskan rawat inap tetapi ada salah satu persyaratan (berkas pasien) yang kutang lengkap, maka apa yang akan dilakukan petugas pendaftaran di RSU Mitra Sejati Medan?” jawaban dari petugas adalah, jika pasien 
adalah pasien BPJS/Asuransi dan pada saat mendaftar ada salah satu persyaratan/berkas pasien yang kurang lengkap atau tertinggal dirumah, maka pasien diharuskan membuat surat pernyataan untuk berkas yang tertinggal dan mengedukasi keluarga pasien bahwa berkas harus diberikan dalam waktu 2 x 24 jam atau sebelum pasien pulang.

Untuk pertanyaan keempat "jika pasien yang mendaftar adalah pasien baru maka apa yang akan dibuat dan diberikan oleh petugas pendaftaran kepada pasien?" jawaban dari petugas adalah tidak ada dikarenakan RSU Mitra Sejati Medan tidak menerapkan pemakaiaan KIB dan KIUP.

Untuk pertanyaan kelima yaitu "sistem penomoran apa yang dipakai di RSU Mitra Sejati Medan?" jawaban dari petugas adalah Sistem penomoran yang pakai di RSU Mitra Sejati Medan adalah Unit Numbering System yang dimana setiap pasien yang berkunjung/berobat pertama kali di RSU Mitra Sejati Medan mendapatkan satu nomor rekam medis dan nomor rekam medis tersebut digunakan selamanya setiap kali pasien berobat ke RSU Mitra Sejati Medan.

Pertanyaan keenam adalah "jika diketahui bahwa pasien memiliki nomor double maka apa yang harus dilakukan oleh petugas pendaftaran?" jawaban dari petugas adalah Jika diketahui bahwa pasien memiliki nomor rekam medis double maka yang harus dilakukan oleh petugas pendaftaran adalah memilih salah satu rekam medis pasien yang paling lama atau yang pertama kali dipakai oleh pasien saat kunjungan pertamanya ke RSU Mitra Sejati Medan.

Petanyaan ketujuh "jika pasien adalah pasien lama dan ingin berobat di RSU Mitra Sejati Medan tetapi petugas tidak dapat menemukan berkas rekam medis pasien tersebut maka apa yang akan dilakukan oleh petugas pendaftaan?" jawaban dari petugas adalah Dikarenakan di RSU Mitra Sejati Medan tidak menggunakan KIB dan KIUP jika ada pasien lama yang ingin berobat kembali di RSU Mitra Sejati Medan maka petugas pendaftaran mencari data pasien menggunakan nomor hp, tahun terakhir berobat dan nomor BPJS pasien bila tidak ditemukan maka petugas pendaftaran memberikan nomor rekam medis baru ke pada pasien.

Pertanyaan kedelapan adalah "jika paseien adalah pasien lama, dan lupa membawa kartu berobat maka apa yang harus dilakukan oleh petugas?" jawabannya adalah mengecek ulang data pasien. Pertanyaan kesembilan mengacu pada sistem penamaan di RSU Mitra Sejati Medan yang dimana pertanyaannya adalah "apakah petugas pendaftaran di RSU Mitra Sejati Medan sudah menerapkan aturan penamaan berkas rekam medis sesuai aturan Permenkes?" jawaban dari petugas adalah belum menerapkan aturan penamaan sesuai ketentuan PERMENKES 269 (2008). Pertanyaan terakhir adalah "apa saja kendala yang sering dialami petugas saat melakukan pendaftaran pasien?" jawaban dari petugas adalah sering dijumpai pasien yang tidak memiliki keluarga/penanggung jawab pasien dan juga pasien yang tidak memiliki identitas.

\subsection{Pembahasan}

Menurut peneliti sistem pendaftran di RSU Mitra Sejati Medan sudah sesuai dengan standar profesi berdasarkan Undang-Undang No.23 Tahun 1992 dimana pedoman yang harus dipergunakan sebagai petunjuk dalam menjalankan profesi secara baik. Dan dilihat dari hasil wawancara peneliti terhadap petugas pendaftaran pasien dimana petugas harus mengidentifikasi pasien dengan cara mewawancarai pasien untuk memastikan terlebih dahulu apakah pasien pernah berobat di rumah sakit tersebut atau baru pertama kali berobat.

Untuk syarat-syarat yang harus dipenuhi pasien agar bisa rawat inap di RSU Mitra Sejati Medan menurut peneliti sudah sesuai karena dilihat dari jawaban responden yaitu, "untuk bisa rawat inap di RSU Mitra Sejati Medan pasien harus memenuhi syarat-syarat pendaftaran yang sudah diatur dalam UU No 44 Tahun 2009 tentang rumah sakit yaitu, 
jika pasien adalah pasien umum maka harus menunjukan KTP pasien dan memberikan panjar biaya perawatan. Namun bila pasien adalah pasien BPJS/Asuransi, harus menunjukan KTP, dan kartu BPJS/Asuransi.

Menurut jawaban responden jika pasien ingin berobat dan diharuskan rawat inap tetapi ada salah satu persyaratan (berkas pasien) yang kutang lengkap, maka pasien diharuskan membuat surat pernyataan untuk berkas yang tertinggal dan mengedukasi keluarga pasien bahwa berkas harus diberikan dalam waktu $2 \times 24$ jam atau sebelum pasien pulang. Menurut peneliti persyaratan itu sudah sesuai karena tiap-tiap rumah sakit memang seharusnya memberikan dispensasi kepada keluarga pasien.

Setelah pasien selasai mendaftar, petugas pendaftaran membuatkan KIUP (Kartu Indeks Utama Pasien) untuk pasien (point poli yang dituju pada bagian belakang KIUP diisi dengan nama ruangan rawat inap yang dipilih) dan mengisi buku register TPPRI (Tempat Pendaftran Pasien Rawat Inap) sesuai dengan data dari pasien. Berkas rekam medis beserta KIUP diberikan ke bagian distribusi untuk dikirim ke ruang rawat inap. Setelah selesai semua berkas termasuk KIUP dikembalikan dan disimpan di bagian filing (berkas rekam medis disimpan berdasarkan No.RM sedangkan KIUP disimpan berdasarkan abjad inisial nama pasien).

Di RSU Mitra Sejati Medan tidak menerapkan pembuatan KIB (Kartu Identitas Berobat) sesuai peraturan PERMENKES No 269 (2008) tentang tanggung jawab perekam medis dalam penyelenggaraan rekam medis meliputi pencatatan identitas pasien ke dalam form Kartu Identitas Berobat (KIB), Kartu Indeks Utama Pasien (KIUP) dan formulir rekam medis. Diketahui pentingnya KIB dan KIUP dapat membantu petugas rekam medis dalam mencari berkas rekam medis didalam rak penyimpanan.

Untuk sistem penomoran di RSU Mitra Sejati Medan menurut peneliti sudah sesuia dengan PERMENKES No.269 (2008), karena sistem penomoran yang dipakai di RSU Mitra Sejati Medan adalah Sistem Unit Numbering System yang dimana setiap pasien yang berkunjung/berobat pertama kali di RSU Mitra Sejati Medan mendapatkan satu nomor rekam medis dan nomor rekam medis tersebut digunakan selamanya setiap kali pasien berobat ke RSU Mitra Sejati Medan. Dari jawaban responden juga diketahui bahwa jika pasien memiliki nomor double maka yang dilakukan petugas pendaftaran adalah memilih salah satu rekam medis pasien yang paling lama atau yang pertama kali dipakai oleh pasien saat kunjungan pertamanya ke RSU Mitra Sejati Medan. Menurut peneliti aturan itu sudah sesuai karena RSU Mitra Sejati Medan menggunakan sistem penomoran Unit.

Dilihat dari jawaban responden jika ada pasien adalah pasien lama dan ingin berobat di RSU Mitra Sejati Medan tetapi petugas tidak dapat menemukan berkas rekam medis pasien tersebut maka apa yang akan dilakukan oleh petugas pendaftaan adalah mencari data pasien menggunakan nomor hp, tahun terakhir berobat dan nomor BPJS pasien bila tidak ditemukan maka petugas pendaftaran memberikan nomor rekam medis baru ke pada pasien. Menurut peneliti itu tidak sesuai dengan aturan PERMENKES 269 (2008) Dikarenakan di RSU Mitra Sejati Medan tidak menggunakan KIB dan KIUP jika ada pasien lama yang ingin berobat kembali di RSU Mitra Sejati Medan maka petugas pendaftaran.

Untuk aturan penamaan RSU Mitra Sejati Medan tidak sesuai karena dilihat dari jawaban responden yang mengaku belum menerapkan aturan sistem penamaan yang sudah ditetapkan PERMENKES 269 (2008).

\section{Hambatan Pendaftaran Pasien di RSU Mitra Sejati Medan}

Berdasarkan hasil penelitian yang telah dilakukan peneliti hambatan hambatan yang sering dialami oleh petugas pendaftaran pasien adalah masih ada ditemukan pasien yang 
tidak memiliki keluarga/penanggung jawab sehingga menyulitkan petugas pendaftaran untuk mengidentifikasi data pasien.

RSU Mitra Sejati Medan belum menerapkan aturan penamaan berkas rekam medis sesuai aturan PERMENKES (2008) tentang Rekam Medis. Yang seharusnya sudah harus diterapkan untuk mempermudah proses pendataan dan pencarian berkas rekam medis pasien yang memiliki nama yang hampir serupa/sama.

RSU Mitra Sejati Medan juga tidak menggunakan KIB dan KIUP sehingga membuat petugas pendaftran yang ingin mendaftarkan pasien lama harus mencari nomor rekam medis pasein dengan menggunakan nama, nomor hp dan nomor BPJS/Asuransi pasien, ini menyebabkan waktu untuk pendaftaran satu pasien akan semakin lama. Hal ini berarti RSU Mitra Sejati Medan seharusnya sudah bisa mulai menerapkan pemakaian KIB dan KIUP dikarenakan pentingnya KIB dan KIUP untuk mempermudah petugas mencari berkas rekam medis pasien.

\section{KESIMPULAN}

1. Pada tahap penamaan pasien di RSU Mitra Sejati Medan belum menerapkan aturan penamaan menurut aturan PERMENKES 269 Tahun 2008.

2. Pada tahapan pendaftaran di RSU Mitra Sejati Medan belum memenuhi aturan PERMENKES 269 Tahun 2008, hanya saja RSU Mitra Sejati Medan belum menerapkan pemakaian KIB dan KIUP.

\section{REFERENCES}

Arikunto. 2007. Prosedur Penelitian Suatu Pendekatan Praktek. Edisi Revisi. Jakarta: Rineka Cipta

Endang, Lsri (2012) Dasar Hulum Penyelenggaraan. Dikutip 12 November 2010 https://.permatakakilangit.files.wordpress.com

Handoyo. 2008. Hukum Tata Negara. Yogyakarta: Universitas Atmajaya.

Hutauruk, P. M., \& Gurning, M. M. B. (2019). Faktor - faktor penghambat pelayanan di tempat pendaftaran pasien bpjs rawat jalan di rumah sakit sari mutiara, lubuk pakam tahun 2019. Jurnal Ilmiah Perekam Dan Informasi Kesehatan Imelda, 4(2), 668-674. http://jurnal.uimedan.ac.id/index.php/JUPIKES/index

Notoatmojo, S. 2010. Metodeoligi Penelitian Kesehatan. Jakarta:Rineka Cipta.

Permenkes RI No. 269/Menkes/Per/III/2008. Rekam Medis. Dari http://perpustakaan.depkes.go.id:8180/bitstream//123456789/1310/1/PMK2690208.pdf. Diakses 28 Mei 2017 Pukul 22:00 WIB.

Ritonga, Z. A. (2016). Rancangan Sistem Informasi Pendaftaran Pasien Rawat Jalan Berbasis Visual Basic Di Rumah Sakit Umum Sundari Tahun 2015. Jurnal Ilmiah Perekam Dan Informasi Kesehatan Imelda, 1(1), 61-66. http://jurnal.uimedan.ac.id/index.php/JIPIKI/article/view/12

Savitri, Citra, Budi. 2011. Manajemen Unit Kerja Rekam Medis. Yogyakarta: Quantum Sinergis Medis. 
Susatyo. 2016. Manajemen Pelayanan Kesehatan Rumah Sakit. Edisi 1. Yogyakarta: Gosyen Publishing.

Sutarman. 2009. Penantar Teknologi Informasi. Yogyakarta: Bumi Aksara.

Tribowo, Cecep. 2012. Perizinan dan Akreditasi Rimah Sakit. Yogyakarta: Nuha Medika.

\section{BIOGRAPHIES OF AUTHORS}

\begin{tabular}{l|l} 
Suheri Parulian Gultom, Gelar Sarjana diperoleh dari Universitas Sumatera Utara. \\
Gelar S-2 diperoleh dari Universitas Sumatera Utara. Saat ini aktif sebagai dosen tetap \\
di Prodi D-III Perekam dan Informasi Kesehatan Universitas Imelda Medan dan \\
menjabat sebagai ketua Prodi.
\end{tabular}

